\title{
A Study Tracking the Learning Status Quo of English Major Students in Normal Universities in China - Taking One of the Normal Universities in Central Region as an Example*
}

\author{
Zhiqiang Zhang \\ The Faculty of International Studies, Henan Normal University, Xinxiang, Henan, China \\ Hao Zhang \\ The Faculty of International Studies, Henan Normal University, Xinxiang, Henan, China
}

\begin{abstract}
In April, 2015, the authors randomly investigated 200 English majors of grades two and three from the Faculty of International Studies at the university where the authors work, using questionnaires to study the learning status quo of English major students in normal universities in China. To understand these students' learning situations in the new era of "The Belt and Road Initiative", in April, 2017 the authors again randomly investigated 200 English major students from the above-mentioned faculty, making detailed comparison and analysis of the two investigations and putting forward some suggestions for the improvement of teaching and learning.
\end{abstract}

Index Terms — normal universities, English major students, learning status quo, tracking study

\section{RESEARCH BACKGROUND}

The core task of higher education development is improving its quality (Kong,2001). Chinese higher education has transitioned from of large-scale expansion to a concentration on mainly improving quality. China has put forward the goal of establishing "world-class universities and world-class disciplines". Many universities and colleges take measures to achieve this goal by reforming the education of teachers, and research how to improve the teaching quality of its hardware and software. This situation ignores the research on teaching objectives to a large extent, which is not in accord with a global focus on learners in recent years. Therefore, this study aims to focus on "learning" rather than "teaching", on the basis of summarizing the related references at home and abroad, using the method of questionnaire survey and taking one of the normal universities in China's central region as an example. This study of the learning status quo of English major students in Chinese normal universities surveys and researches existing problems, and puts forward many corresponding measures.

\section{ReSEARCh Motivation AND SignificANCE}

English teaching in universities in China has always been criticized. It has been evaluated as "time-consuming but inefficient" (Du, 2017). English majors' teaching has also received a lot of criticism from society and some experts. Some university teachers, and employers outside universities, have criticized the language foundation and proficiency of English major students. For example, professor Cai Jigang wrote papers to point out many drawbacks of English majors' teaching in China (Cai,2004).

Since 2010, English as a major has been listed as the "red sign" major of the college entrance examination four times. It is also a high unemployment risk major, because its employment rate, monthly income and employment satisfaction are rather lower than comparable majors. One reason may be the oversupply of graduates as well as the fact that the quality of training does not satisfy the demand of job positions. But despite this, students have a high passion to register for English majors in recent years, especially in normal universities. So the questions why students choose English majors, how they learn, and whether these two questions are related to the quality of university students are also the focus of this research. This study not only considers theoretical approaches to teaching and learning, but also plans to improve their quality.

The authors searched the relevant references on CNKI .When taking "English majors in normal university" as the

\footnotetext{
* This paper is one of the achievements in the research on the curriculum system and content reform concerning the Chinese and foreign culture courses offered for pedagogical students of English major based on the implementation of "The Belt and Road Initiative", the provincial project of The Education Department of Henan Province presided by the author.(Project number : 2017-JSJYZD-015)
} 
searching theme, there are 124,108, 130, 135 and 122, amounting to 619 relevant papers respectively. Most of them are masters' papers and journals, and master's papers have a higher proportion than journals. When the authors searched the theme "research on learning status quo of English majors' students in normal universities", they found that the earliest paper was published in 2006, and the research mainly studies the ability of students' independent learning to write English. There are only 43 relevant papers in CNKI from 2006 to 2016. The authors read these papers carefully and found that they just researched either teaching or learning but not both. This paper researches both teaching and learning in Chinese academies. Therefore, to a certain extent, this paper can compensate and perfect the related research in China(Si,2016).

\section{DESIGN AND IMPLEMENTATION OF INVESTIGATION AND RESEARCH}

The authors selected a normal university in the central province in China; the students are from all over the country. The university is in the upper-class level of Chinese normal universities ranking, therefore this study has a certain representativeness.

\section{A. Subjects and Tool of the Survey}

The subjects of this survey are 200 students of English major students in the Faculty of International Studies at the University. The tool is questionnaire, and issued randomly. The investigated subjects covered all classes of two grades of English majors. The data are authentic and highly reliable. In this study, a total of 200 questionnaires were issued and 195 valid questionnaires were collected. The effective ratio of the questionnaire is $97.5 \%$.

In order to ensure the rationality and feasibility of the design of the questionnaire, the authors carried out a pre-survey in a small range several times before issuing questionnaires formally. According to the survey results and the interviews with students, the authors adjusted the questionnaire to gain more objective and comprehensive data. In order to make the surveyed subjects treat this survey seriously and ensure the authenticity and accuracy of data, the issue, questionnaire completion and collection were conducted during lesson breaks. Before issuing the questionnaire, the authors illustrated details and explanation of each part of it. In order to ensure the accuracy of data statistics, the data statistics adopt the method of multi-person cross validation $(\mathrm{Qu}, 2012)$.

\section{B. Description of Questionnaire Design}

The questionnaire is divided into two parts, the first part is the personal information of students, including grades of students, gender and age; the second part is composed of 20 questions, and divided into objective and subjective questions. Subjective questions are open questions, mainly involving the students' learning motivation; objective questions are multiple-choice questions, involving five aspects: learning state, learning concept, reading books, classroom situation, Internet surfing.

\section{The Results of The InVESTIGATION AND ITs COMPARATIVE ANALYsis}

The authors not only made a detailed data analysis of the investigation results, but also compared the results with those of the study completed by the author two years ago.

\section{A. Learning State}

\section{About learning time}

The time that students spend in learning is as follows, $47 \%$ of the students can guarantee the daily learning time is 1-3 hours, the time that $17 \%$ of the students spend on learning is more than 3 hours, and the time that $36 \%$ of the students spend on learning is less than one hour. In learning time, the proportion of students' learning time in different subjects is increasing. It is worth mentioning that compared with the results two years' before, the proportion of students who reported no interest in learning has declined from $5 \%$ to 0 . This indicates that on the whole, students have made a considerable improvement in learning.

2. How to plan students' spare time

About spare time arrangement: $70.6 \%$ of the students recorded spending much time in doing homework and reading. This shows that most students' learning positivity and learning state have improved on the whole. In addition, about $48.4 \%$ of the students use spare time to acquire extra knowledge, and participate in all kinds of campus activities and part-time jobs. There are also some students who travel around near places at weekends, the proportion is $43.7 \%$. It is obvious that different students have different schedules, which is directly related to factors such as gender, personal interest and so on. In contrast, students recorded the planning and arrangement of their spare time as being more rational and organized than the results two years' before, which is directly related to the growing engagement of students with their learning in the new era.

3. Issues with learning

A majority of students recorded that they found difficulty with planning time; $43 \%$ of the students lacked motivation to learn. In addition, $28.1 \%$ of the students consider that this is directly related to weak self-study ability and less scientific learning method. $9.6 \%$ of them thought that a lack of knowledge of how to learn leads to their learning troubles. The proportion of students recording suffering from learning troubles due to various factors is decreasing by 
contrast. The improvement of this phenomenon is related to the increasing importance of mental health education for university students in recent years.

4. Solving learning difficulties

About $81.3 \%$ of the students solve their learning difficulties through consulting relevant books and materials; the proportion of students who take the initiative to ask for teachers or other students is $72.3 \% ; 23.7 \%$ of the students choose to passively accept the teacher answering questions in the classroom; and only 5\% of the students do not want to solve their own learning difficulties. In the last two years students have been influenced by various factors, and can adjust their learning attitude actively. This is directly related to our university's strong learning atmosphere and the increased emphasis on students' learning.

5. The completion of homework

The percentage of students who can complete homework independently is about $82 \%$, and $27.9 \%$ of the students choose to make a differential treatment on homework of different professional courses. Only $2.1 \%$ of the students do not do homework or copy others' homework. In contrast, the percentage of the students who can do their homework independently and distinguish differently from different subjects increases by 6 percentage points and 2.3 percentage points respectively. Meanwhile, the proportion of the students who don't do homework or copy others' homework has also decreased by 1.7 percentage points.

6. Views on learning condition

Only $20.9 \%$ of the students feel very satisfied with learning condition; about $70.7 \%$ of the students are basically satisfied, but they need to seize the time to solve the problems of learning objectives that are not clear; $8.3 \%$ of the students are disappointed with their current learning situation. Even Some students report guilt and negativity. In general, more and more students recorded that be satisfied or basically satisfied with their learning.

\section{B. Learning Concept}

1. The idea and concept of language aptitude and efforts

$46.5 \%$ of the students think that possessing linguistic talents does not necessarily lead to competent language learning. This result shows that they do not agree there is a relationship between language aptitude and learning English well. $53.5 \%$ of the students think that hard work plays an important and even decisive role in foreign language learning. This shows that more and more students think that after hard work, English can be learned well.

2. Strategy and concept of learning management

$82.5 \%$ of the students think that the effective use of management strategies plays an important role in learning a foreign language. It is vital to have long-term and short-term learning goals to learn foreign languages. At the same time, they think that students should apply what they have learned about learning positivity and management to their own situations, and need to constantly sum up their own progress and identify their problems with learning, and reconsider whether their own learning methods are effective. This shows that most of the students have an active learning awareness. In contrast, the students studied appear able to use the learning management strategies better and more scientifically, which has a direct relationship with the education of newly enrolled students.

3. Native concept, formal training concept and function training concept

$45 \%$ of the students think that they can not understand texts through translation, because it is not a good way to learn a foreign language. $55.6 \%$ of the students think in order to learn and improve foreign language, you need to regard Chinese as the intermediary in order to do listening, speaking and writing practice. With regards to how to improve their practice, $87.6 \%$ of the students think that repeated practice can improve listening and speaking abilities. With regards to functional practice, the high grade students show more confidence in its importance than the low grade students. This shows that both the concept of formal practice and functional practice can improve the students' English ability(Zhang,2015).

\section{Reading Books}

1. The frequency of going to the library every week

$70.1 \%$ of the students reported that they went to the library every week, and $39.9 \%$ of the students go to the library quite frequently, about 4 to 5 times a week. In contrast, more students go to the library to read and consult some related books more frequently.

2. Extracurricular books reading

$70.9 \%$ of the students reported choosing literary works; $63.2 \%$ of the students choose textbooks and professional books. $35.1 \%$ of them are interested in literature, history, philosophy, psychology and other related books. Students read more and more books, and the scope of knowledge involved is becoming more and more extensive.

3. The quantity of reading professional books per semester

$57.5 \%$ of the students reported reading 1 to 2 professionally related books, but the proportion of students who never read professional books is $24.3 \%$, and the number of students who reported reading read three or more professional books account for $25.8 \%$. In the field of reading professional books, more students are learning their professional knowledge more thoroughly and comprehensively than before. This can improve their employment competitiveness greatly (Zhang,2015). 


\section{Situation in Classroom}

1. Problems in the classroom

$38.9 \%$ of the students think that the atmosphere of some teachers' lessons is rather boring, which causes that their learning interest and listening efficiency to greatly decrease. $21.1 \%$ of the students think that knowledge lectured on by teachers lacks an authoritative basis. In the last two years, with the continuous improvement of teaching quality and teaching reform, however, the teachers in this university have also paid more attention to the establishment of effective organization and knowledge system in classroom teaching. So fewer and fewer students feel bored during classes.

2. The situation of being late, leaving early and absence from lessons

$27.8 \%$ of the students think that these situations can be understood. But $72.2 \%$ of the students disagree with this view. They believe that these practices not only disrespect teachers, but also disrupt the normal order of the classroom. In comparison, more and more students have recorded being able to respect their teachers.

3. The main reasons for skipping class

$67.4 \%$ of the students reported lacking learning motivation; $52.3 \%$ of the students have different opinions on the teaching methods of teachers. $35.4 \%$ of students choose to skip class because of participating in campus activities. $25.7 \%$ of the students are weary of studying. $16.9 \%$ of students are addicted to online games. It is worth mentioning that boys have a large proportion in skipping classes.

4. The situation of the surrounding students being late

About $97.8 \%$ of the students think that all the students in the class are quite punctual. They always arrive at the classroom 5 to 10 minutes in advance. And 2.2\% of the students could be late occasionally. With the development of the learning atmosphere and strictness of the discipline, the phenomenon of student's being late has been improved despite the occasional lateness of individual students.

5. The view of checking class attendance

$78.2 \%$ of the reported being in favor of the teachers or the monitor checking the attendance before class or during the break time between classes. They think this way can play a supervised role in a larger extent. But $21.8 \%$ of the students think that checking class is not necessary, and class attendance should be governed by students own conscientiousness. Most of students support to check attendance before class or during break time. This indicates that most students in this university have been more and more in favor of the importance of the discipline of checking attendance(Zhang,2015).

\section{E. Internet Use}

1. The time of using Internet in daily life

$93.9 \%$ of the students reported being able to limit their daily internet use to within two hours; $6.1 \%$ of the students spend 3 hours or even more on Internet. This compares favorably with the situation two years previously, with more students now reporting increased participation in activities in campus, consulting and reading professional books in the library, so students have been able to arrange their spare time and control the time of using Internet reasonably in recent two years. They also report that self-control have been quite strengthened.

2. Situation of the purpose on using the Internet

$65.5 \%$ of the students use the Internet to find relevant and other aspects of learning material; $47.8 \%$ of the students need to use the Internet to browse news for personal interest. But the students who regarded Using the internet as recreational decreased significantly, accounting for 55.6\%, and this cohort of students is mainly practicing English listening and speaking through watching US TV series, listening to English songs and films etc. Over the past two years, the main purpose of using the internet is mostly searching materials related to English. This indicates that students' ability to collect material and conduct scientific research has improved greatly.

\section{F. Learning Motivation}

There are a number of research studies in this field. In Gardner's (1985) opinion, motivation consists of three factors: the desire to language learning, the attitude to language learning, and the intensity of motivation (Gardner, 1985). The authors reorganized and summarized according to answers, and conducted a careful and detailed analysis of these answers. The result shows that the higher grade students' internal interest in English learning motivation is better than the lower grade students, which indicates that students' interest in learning English can be improved with increased understanding of language itself and the culture of English-speaking countries. Besides, there is an increasing trend in the motivation of language learning in order to travel abroad. Some students have had plans and goals for going abroad since the being freshmen. Their motivation for English learning is also becoming more and more important as the motivation of going abroad is becoming clearer and clearer(Zhou,2011).

\section{Analysis of StUdents' LeARning Problems}

\section{A. As Reported by Students}

First, there are significant differences in reporting language learning difficulties according to students' gender in normal universities.. The results of the survey show that girls are better than boys in their attitudes, and learning status. This is because in terms of language learning, female students have a gender advantage over male students as a whole. Secondly, there are slight differences among different grades of the students in their spare time planning, learning 
troubles and reading books. This result is mainly due to the time it takes for students to adapt to new life after going to university, and understand the pressure of future employment gradually. Thirdly, most college students are influenced by the thought formed in senior high school, which is mainly due to the different ways of thinking taught by the science and liberal arts curricula, and which have a great influence on their career planning in future. Finally, there is an important additional factor: the impact of different families' economic and social status. University students in a high socioeconomic status families are better than those of lower status in solving learning difficulties, learning goals setting and class attendance. This is mainly related to the degree of their parents' education and family attitudes towards learning(Sun,2016).

\section{B. As Reported by Teachers}

University students' satisfactions in learning and towards teachers are closely related to the teaching methods used by teachers. The students are more dissatisfied with the traditional teaching mode, and value alternative teaching methods, for example, those which promote independent, cooperative and experiential learning.

\section{As Reported by Society}

To a certain extent, the differences of economic development between urban and rural areas will have a decisive impact on the quality of teachers, the hardware and software of schools, and the learning environment of students. Furthermore, the level of economic development will have an effect on differences between urban and rural education environment. To be specific, university students from cities are more skilled in independent inquiry than students from rural areas; this has direct relationship with attention on quality education and the quality of the degree (Sun,2016).

\section{Feasible Measures to Improve Students’ Learning Status Quo}

\section{A. Improving Students' Levels of Attainment: Students' Perspectives}

1. Enhancing Internal motivation to learn

The results of this study suggest that students should focus on cooperative learning and inquiry learning, feel the changes in learning and life by the variety of inquiry activities. This will stimulate their inner passion, enhance their motivation of internal interest, cultivate their interest in English language and culture, and help them to love learning English.

2. To adjust actively the way of learning

Our study recommends that students should combine their own learning characteristics with professional learning rules, actively transform their learning concepts, lay emphasis on independent learning and adopt more scientific and efficient learning ways.

\section{B. Improving Student Attainment: Teachers' Perspectives}

1. To improve the teaching model and stimulate the enthusiasm of students' participation.

In the classroom teaching, teachers should actively create inquiry learning situations that are helpful for university students to participate in, which can make students feel the pleasure of the learning process personally, and stimulate universities students' learning enthusiasm, especially the students from rural areas. At the same time, teachers should also strengthen the guidance for universities students, actively encourage and cultivate students' scientific research consciousness and ability.

2.To increase the humanistic care for the disadvantaged universities students and make a real "Good Teacher and Helpful Friend"

Teachers should focus on the deepening and implementation of teaching reform, and change their previous teaching modes. In the teaching process, teachers should teach students in accordance with their aptitude. Specifically, teachers should take the initiative to gain information regarding their students' social and economic situations. If the majority is from the city, the teacher should highlight cooperative learning in the teaching process; but if the majority comes from the rural areas, it is necessary to put more emphasis on inquiry learning in the teaching process, and pay attention to giving guidance at the same time. In addition, for the students with special characteristics, teachers should give more humanistic care, so that "no one student is left behind".

\section{Improving Student Attainment: University Management Perspectives}

1. To set up a variety of courses in accordance with the development of the era and society

The universities' educational administration department should set courses scientifically and reasonably in accordance with the different learning characteristics of all colleges and majors, and increase the proportion of elective courses. For example, adding related courses, in order to satisfy students' interest in English learning; creating better learning atmosphere is able to promote students to learn independently. At the same time, extending the elective lessons into extracurricular activities and social practice( $\mathrm{Lv}, 2012)$.

2 . To strengthen the service consciousness of teachers

In order to improve education quality, universities should take feasible measures to improve students' learning satisfaction. The universities authorities should pay close attention to collective and sorting students' opinions and 
suggestions, using effective and targeted research. Secondly, university managers should guide students to participate in research projects, adhere to the principle that 'students are the main part of learning', attach importance to the cultivation and development of students' potential, thereby achieving respect for students in a real sense. Finally, university managers should pay attention to the construction of systems in university and perfecting systems to evaluate teachers, promoting teachers can gain more excellent teaching skills and levels, which helps to change students' learning methods and education quality will improve.

\section{CONCLUSION}

This paper has tracked attitudes to and achievements in learning of a group of English majors in a Chinese normal university. The authors have obtained detailed first-hand survey data, and through the analysis of the data, especially compared with data obtained two years previously, we can see that the students how students learn, how they conceptualize learning, the number of books they read, their class attendance plus their use of the internet: all these have changed compared with compared with two years ago. There are, however, some problems which have not changed and which have not been effectively resolved. That this is so is not only related to how students learn and conceptualize learning, but also to the fact that teachers are still not paying sufficient attention to studies of students' learning. In order to change and optimize the status quo of students' learning fundamentally, society, universities and teachers should also update the curriculum, their concept of what teaching is as well as teaching methods. But the most fundamental need is to strengthen the students' learning motivation and help students learn to learn.

This research has only investigated students in one university, the sample data quantity is not enough. Because the survey of teachers has not been conducted, so it is hard to find out whole problems in teaching and learning of English majors. Nevertheless, the authors hope that this research can bring some references and inspirations to our university teachers and managers, and hope this study can arouse more scholars to pay more attention to students "learning". After all, students are the subject of learning. The improvement of the teaching quality we expect still depends on students' love for learning and their ability to learn.

\section{ACKNOWLEDGEMENTS}

I would like to express my gratitude for the help of Professor Rob Hardy.

Rob Hardy obtained his BA in English from Cambridge University and his MA and PhD degrees from Cardiff University. He was formerly the Assistant Principal for Higher Education at the Bournemouth and Poole College, and now divides his time between China and the UK, teaching and researching.

\section{REFERENCES}

[1] Cai Jigang. (2004). Generally Discuss Basic Principles and Spirit of The Teaching Requirement for College English. Foreign Languages and Their Teaching, 1, 18-22.

[2] Du Hui, Li Ningjun. (2017). The Change and Enlightenment of Western Language Teaching Theory in One Hundred Years. Journal of Tianjin Foreign Studies University, 1, 61-67.

[3] Gardner, R.C. (1985). Social Psychology and Second Language Learning: The Role of Attitudes and Motivation. London: Edward Arnold.

[4] Kong Qiping. (2001). Discuss On the Change of Learning Style. Global Education, 8, 19-23.

[5] Lv Linhai, Gong Fang. (2012). On Learning Methods in Higher Education: Origin, Views and Future Trends. Journal of Higher Education, 2, 58-66.

[6] Qu Ping. (2012). An Investigation and Analysis on English and Non-English Major's Motivation of English Learning in A Normal University. Journal of Henan Institute of Science and Technology, 8, 101-103.

[7] Si Man. (2016). Investigation and Research on The Status Quo of Study Freedom of Undergraduates in N University. Nanjing Normal University.

[8] Sun Haixia. (2016). College Students' Learning Status Quo Investigation and Improvement Strategy Research. Harbin Normal University.

[9] Zhang Hao. (2015). Investigation and Research on The Learning Concept of English majors Students In Normal Universities. Spiritual Leaders, 12, 50-51.

[10] Zhang Hao. (2015). Investigation and Research on The Status Quo of Students in Ordinary Colleges and Universities: Taking Study Style Construction as The Background. Journal of Harbin Vocational \& Technical College, 3, 114-115.

[11] Zhou Yan, Gao Yihong, Zang Qing. (2011). The Development of Chinese Undergraduates' Motivation for English Learning in Their Junior and Senior Years: Finding From A Longitudinal Study in Five Universities. Foreign Language Teaching and Research, 2, 251-260+320-321.

Zhiqiang Zhang was born in Xinxiang, China in 1964. He received his PH.D. degree in translation studies from Nanjing Normal University, China in 2010.

$\mathrm{He}$ is currently a professor in Faculty of International Studies, Henan Normal University, Xinxiang, China. His research interests include translation studies, English teaching, comparative literature, etc.

Dr. Zhang is an expert member of Translators Association of China and a lifelong member of China Association for Comparative 
Studies of English and Chinese.

Hao Zhang was born in Xuchang, China in 1994. He is an MA graduate student of foreign language and literature in Faculty of International Studies, Henan Normal University, Xinxiang, China. His research interests include translation studies, English teaching. 